\title{
Current Research Progress on microRNAs in Huntington's Disease
}

\author{
Jiang Bingbing* \\ Faculty of Life Science and Technology, Kunming University of Science and Technology, China
}

*Corresponding author: Jiang Bingbing, Faculty of Life Science and Technology, Kunming University of Science and Technology, China

\begin{abstract}
ARTICLE INFO
Received: 慧 December 16, 2019

Published: 幽January 06, 2020

Citation: Jiang Bingbing. Current Research

\section{ABSTRACT}

Huntington's Disease (HD) is a monogenic genetic disease of neurodegenerative disorders caused by repeated amplification of CAG trinucleotides in the first exon of the huntingtin gene (HTT), and there are no treatments which could forestall or slow Huntington's disease. MicroRNA (miRNA) plays an important role in the posttranscriptional regulation of genes whose expression is related to the pathological process of Huntington's disease.
\end{abstract} Progress on microRNAs in Huntington's Disease. Biomed J Sci \& Tech Res 24(2)2020. BJSTR. MS.ID.004014.
Keywords: microRNA; Huntington's Disease; Regulation Mechanism

\section{Huntington's Disease}

Huntington's Disease (HD) is caused by repeated amplification of the (CAG)n trinucleotide in the first exon of the huntingtin gene (HTT), also classified as polyglutamine (PolyQ) disease [12]. HD occurs mostly in middle-aged people, with an average age of onset of 45 years [1-3]. In 1872, the American doctor George Huntington described the clinical features of HD and people have learned more about the disease and named it after Huntington [4]. It was not until 1993 that HTT, the pathogenic gene for HD, was found located at chromosome 4p16.3 [5]. The size of (CAG)n in the first exon of HTT not only affects the phenotype and function of cells, but also determines the age of onset of HD patients [36]. The clinical symptoms of HD are mainly chronic progressive aggravated dyskinesia, mental disorder and cognitive impairment. Patients have a life span of approximately 20 years after the onset of disease symptoms [7]. There is currently no cure for HD. People mainly perform multidisciplinary assessment and comprehensive management of patients' symptoms to maximize the quality of life of patients.

\section{Generation and Function of microRNA}

MicroRNA (miRNA) is a family of single-stranded non-coding RNAs encoded by endogenous genes, with a length of approximately 22 nt. Mature miRNAs are loaded into RNA-induced silencing complexes (RISCs), and RISCs are guided to the binding sites of their target gene transcripts to degrade target gene transcripts or inhibit its protein translation, playing an important role in regulating gene expression at the post-transcriptional level [8-9]. More than $60 \%$ of human protein-coding genes are predicted to be targets of miRNAs, and it is clear that changes in miRNA expression will have an important impact on life [10]. In recent years, miRNAs have been found to play a key role in physiological and pathological processes related to brain function [11].

The production of miRNAs in the human body follows a twostep process, which is completed in the nucleus and cytoplasm in turn. In the nucleus, miRNA is transcribed by RNA polymerase II or RNA polymerase III through the promoter of itself or the host gene. Most miRNAs are transcribed by RNA polymerase II. Transcription products are called primary miRNAs or pri-miRNAs. Ribonuclease III Drosha cleaves pri-miRNA in the nucleus to form a stem-loop structure intermediate called miRNA precursor or pre-miRNA. PremiRNA is transported from the nucleus to the cytoplasm by the nuclear proteins Exportin-5 and Ran-GTP (GTP-binding nuclear protein Ran). In the cytoplasm, another ribonuclease III Dicer further cuts the stem-loop structure intermediate and partially cuts off the ring structure to form an incompletely matched double strand. The double strand is called miRNA:miRNA* complex. miRNA 
is recognized by AGO2 (Argonaute-2) protein and loaded into RISC, and the other strand of miRNA* is generally rapidly degraded [12] miRNAs regulate gene expression at the post-transcriptional level, mainly by interacting with the 3'-Untranslated Region (3'-UTR) of the target gene transcripts through its seed region, and with 5'-UTR interactions are rare. If miRNA and mRNA have a high degree of complementary pairing, mRNA will be degraded. Otherwise miRNA will inhibit the protein translation of mRNA [13-14].

\section{MiRNAs that are Dysregulated in HD}

Identifying miRNAs whose expression is dysregulated in HD will facilitate a deeper understanding of the molecular mechanisms of pathogenicity, providing evidence for the diagnosis and treatment of HD. Current research suggests that the dysregulation of miRNA expression in HD may be due to two reasons. One reason is the abnormal expression of miRNA-producing machines in HD. Lee et al. used wild-type mice as controls and found that the expressions of Drosha, DGCR8 (DiGeorge syndrome chromosomal critical region 8), and Exportin-5 protein were up-regulated in 5-month-old HD mouse models. It was also observed that miRNA expression in the disease models was generally up regulated. They found that Dicer protein expression was down-regulated in a 12-month-old HD mouse model, while an overall downregulation of miRNA expression in the disease models was observed [15]. In the HD mouse models, the miRNA-producing machines are highly consistent with miRNA expression changes, indicating that the miRNA production pathway has changed and lead to miRNA expression disorders. These miRNA-producing machines may be affected by $\mathrm{mHtt}$ (mutated huntingtin protein).

On the other hand, the reason is that the transcriptional regulation of miRNA in HD is abnormal. Pircs et al. found that the formation of aggregates by $\mathrm{mHtt}$ can disrupt cell autophagy and cause abnormal accumulation of AGO2 protein. AGO2 is a key factor for miRNA function in RISC, and its abnormal accumulation will change the expression and activity of miRNA [16]. (CAG)n in mHTT (the mutated huntingtin gene) can transcribe miRNAs, which may be an important mechanism for the disruption of miRNA regulation in HD patients [17].

\section{ISSN: 2574-1241}

DOI: 10.26717/BJSTR.2020.24.004014

Jiang Bingbing. Biomed J Sci \& Tech Res

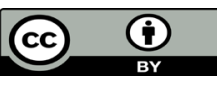

This work is licensed under Creative Commons Attribution 4.0 License

Submission Link: https://biomedres.us/submit-manuscript.php

\section{References}

1. Bates GP, Dorsey R, Gusella JF, Hayden MR, Kay C, et al. (2015) Huntington disease. Nat Rev Dis Primers 1: 15005

2. Yushchenko T, Deuerling E, Hauser K (2018) Insights into the Aggregation Mechanism of PolyQ Proteins with Different Glutamine Repeat Lengths. Biophys J 114(8): 1847-1857.

3. Lee JM, Correia K, Loupe J (2019) CAG Repeat Not Polyglutamine Length Determines Timing of Huntington's Disease Onset. Cell 178(4): 887-900.

4. Owecki MK, Magowska A (2019) George Huntington (1850-1916). J Neurol 266(3): 793-795.

5. Macdonald ME, Ambrose CM, Duyao MP, Myers RH, Lin C, et al. (1993) A novel gene containing a trinucleotide repeat that is expanded and unstable on Huntington's disease chromosomes. Cell 72(6): 971-983.

6. Ooi J, Langley SR, Xu X, Utami KH, Sim B, et al. (2019) Unbiased Profiling of Isogenic Huntington Disease hPSC-Derived CNS and Peripheral Cells Reveals Strong Cell-Type Specificity of CAG Length Effects. Cell Rep 26(9): 2494-2508.

7. Walker FO (2007) Huntington's Disease. Semin Neurol 27(2): 143-150.

8. Bartel DP (2004) MicroRNAs: genomics, biogenesis, mechanism, and function. Cell 116(2): 281-297.

9. Ambros V (2004) The functions of animal microRNAs. Nature 431(7006): 350-355.

10. Friedman RC, Farh KK, Burge CB, Bartel DP (2009) Most mammalian mRNAs are conserved targets of microRNAs. Genome Res 19(1): 92-105.

11. Saraiva C, Esteves M, Bernardino L (2017) MicroRNA: Basic concepts and implications for regeneration and repair of neurodegenerative diseases. Biochem Pharmacol 141: 118-131.

12. Costa V, Scorrano L (2012) Shaping the role of mitochondria in the pathogenesis of Huntington's disease. EMBO J 31(8): 1853-1864.

13. Vishnoi A, Rani S (2017) MiRNA Biogenesis and Regulation of Diseases: An Overview. Methods Mol Biol 1509: 1-10.

14. Gulyaeva LF, Kushlinskiy NE (2016) Regulatory mechanisms of microRNA expression. J Transl Med 14(1): 143.

15. Lee ST, Chu K, Im WS, Yoon HJ, Im JY, et al. (2011) Altered microRNA regulation in Huntington's disease models. Exp Neurol 227(1): 172-179.

16. Pircs K, Petri R, Madsen S, Brattås PL, Vuono R, et al. (2018) Huntingtin Aggregation Impairs Autophagy, Leading to Argonaute-2 Accumulation and Global MicroRNA Dysregulation. Cell Rep 24(6): 1397-1406.

17. Nahalka J (2019) The role of the protein-RNA recognition code in neurodegeneration. Cell Mol Life Sci 76(11): 2043-2058.

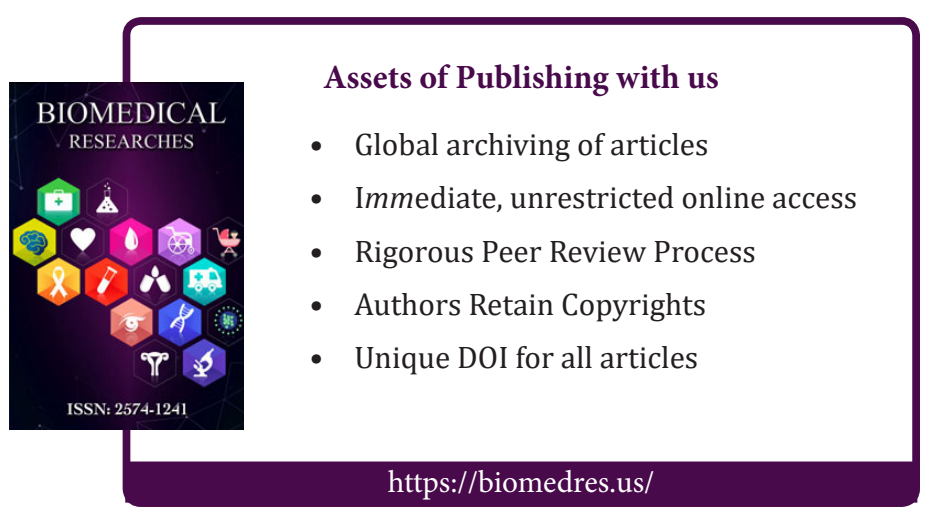

